\title{
Diversificación de ingresos de los productores como estrategias de desarrollo rural*
}

\author{
Erika Román-Montes de Oca \\ Docente Investigador Universidad Autónoma del Estado de Morelos, Cuernavaca, Morelos - México. \\ kikaromel7@hotmail.com (D) https://orcid.org/0000-0002-9490-6422 \\ Jesús Eduardo Licea-Resendiz \\ Docente Investigador Universidad Autónoma del Estado de Morelos, Cuernavaca, Morelos - México. \\ jesus.eduardo@uaem.mx (D) https://orcid.org/0000-0002-4468-3435
}

\author{
Fernando Romero-Torres \\ Docente Investigador Universidad Autónoma del Estado de Morelos, Cuernavaca, Morelos - México. \\ fromerot@uaem.mx D https://orcid.org/0000-0002-4389-3369
}

RES U M E N

Como respuesta a la crisis económica que se vive en las diferentes comunidades del país, los productores de la comunidad de Tanhuato Michoacán, México, diversifican las actividades productivas como estrategias de reproducción para lograr un desarrollo rural. La investigación que se llevó a cabo fue de tipo exploratoria descriptiva, se hicieron 40 encuestas de las cuales 10 fueron a manera de entrevista; se determinó que las actividades económicas que realizan las unidades familiares consisten principalmente en la siembra de alfalfa, maíz y trigo; asimismo, combinan diferentes cultivos y, en menor participación, el trabajo asalariado. Con ello los productores buscan mejorar los ingresos desde sus propias capacidades, recursos y conocimientos.

Palabras clave

Actividades económicas; seguridad alimentaria; estrategias de reproducción; desarrollo rural

Clasificación JEL

Q0I, QI2, Q18

\section{Diversificaction of income of producers as rural development strategies}

A B S T R A C T

In response to the economic crisis experienced in different communities of the country, producers in the community of Tanhuato Michoacán, Mexico, are diversifying their productive activities as reproductive strategies to achieve rural development. The research that was carried out was of an exploratory descriptive type. 40 surveys were done of which 10 were interviews; it was determined that the economic activities that the family units carry out consist mainly of the sowing of alfalfa, corn and wheat; likewise, they combine different crops and, in less participation, the salaried work. With this the producers seek to improve their income through their own capacities, resources and knowledge.

KEYWORDS

Economic activities; food safety; reproduction strategies; rural development

JEL Classification

Q0I, Q12, Q18

Recibido: 02/05/2020 Aceptado: 01/06/2020

* Este es un artículo Open Access bajo la licencia BY-NC-SA (http://creativecommons.org/licenses/by-nc-sa/4.0/)

Cómo citar este artículo: ROMÁN-MONTES DE OCA, Erika; LICEA-RESENDIZ, Jesús Eduardo; ROMERO-TORRES, Fernando. Diversificación de ingresos de los productores como estrategias de desarrollo rural. En: Entramado. Julio - Diciembre, 2020 vol. I6, no. 2, p. I26-14| 


\section{Diversification of income of producersas rural development}

\section{strategies}

RES U M O

Como resposta à crise económica nas diferentes comunidades do país, os produtores da comunidade de Tanhuato Michoacán, México, estão a diversificar as suas actividades produtivas como estratégias reprodutivas para alcançar o desenvolvimento rural. A investigação realizada foi de tipo exploratório e descritivo, foram realizados 40 inquéritos, 10 dos quais através de entrevistas; foi determinado que as actividades económicas que as unidades familiares realizam consistem principalmente na sementeira de alfafa, milho e trigo; do mesmo modo, combinam diferentes culturas e, em menor participação, trabalho assalariado. Com isto, os produtores procuram melhorar os seus rendimentos a partir das suas próprias capacidades, recursos e conhecimentos.

Palavras-chave

Actividades económicas; segurança alimentar; estratégias de reprodução; desenvolvimento rural Classificação JEL $\mathrm{Q} O \mathrm{Q}, \mathrm{Q}|2, \mathrm{Q}| 8$

\section{Introducción}

La falta de políticas públicas que beneficien a los pequeños y medianos productores ha originado mayor pobreza y hambre en las comunidades rurales, ya que se le sigue dando prioridad a la importación de alimentos y no la reactivación económica local. El problema de dependencia alimentaria genera la volatilidad de precios que impacta en el poder de compra de las exportaciones y en consecuencia se incrementa el valor de los alimentos o disminuye la disponibilidad de estos; asimismo, se detonan procesos inflacionarios que condicionan la capacidad de acceso real a los alimentos por parte de los grupos poblacionales y territorios vulnerables (IICA, 20I2).

Los productores son los principales interesados en buscar reactivar las economías de sus comunidades, aun con los retos que ello representa: altos costos de producción, inestabilidad de los precios de venta (principalmente de los productos agropecuarios), competitividad de productos $y$, por supuesto, los efectos por el cambio climático que cada día son más contundentes. Cabe resaltar que cada comunidad tiene sus propias capacidades, potencialidades y recursos, de los cuales hacen uso para su desarrollo, entendiéndose como desarrollo el "proceso de mejoramiento en la calidad de vida de los sujetos, lo que supone que los sujetos tienen posibilidades de satisfacer sus necesidades: por ello el desarrollo debe considerar al hombre como fin del proceso" (Zarate, 2005, p. 196). Para mejorar la calidad de vida es trascendental considerar la optimización de los aspectos económicos, sociales, de salud, vivienda, disponibilidad y accesibilidad de alimentos nutritivos, educación, recreación, entre otros; lo cual se puede conseguir con la participación de todos los actores involucrados, los habitantes de la comunidad, las empresas comerciales, el gobierno y las organizaciones sociales.

Con el propósito de cubrir las necesidades básicas, las familias rurales buscan cada día innovar en diferentes actividades económicas, las cuales conforman un conjunto de estrategias que siempre se han presentado, pero que cada día se ve más impactado por los cambios y tendencias económicas, políticas y culturales que se han generado a partir del neoliberalismo. Este fenómeno ha suscitado crisis en diferentes ámbitos: ambientales, desarrollo humano, económicos, productivos y competitivos. Como menciona Rubio (2013), el neoliberalismo originó “desestructuración de un amplio grupo de pequeños productores que carecieron de recursos para impulsar la producción, después de la quiebra a la que fueron sometidos. Se fortaleció entonces el autoconsumo como una medida para resistir el declive de los precios" (p. 57), y se diversificaron las estrategias para generar ingresos, entendiendo por diversificación al cúmulo de actividades que realizan los pobladores de las comunidades rurales con la finalidad de obtener beneficios o ingresos de fuentes alternas a la actividad de producción principal que desarrollan; con ello, reducen la vulnerabilidad por depender de una sola fuente de ingresos que sustente el gasto familiar (Ellis, 2000; Niehof, 2004).

Las familias diversifican sus actividades de acuerdo con las demandas productivas del sector agropecuario, pero esto depende también de los recursos con los que cuenten, lo cual se corrobora en otros estudios realizados sobre la diversificación de actividades como alternativas para la subsistencia de las unidades familiares. Por ejemplo, el 
caso de una publicación realizada en cuatro localidades rurales del Estado de Oaxaca, México; donde mencionan Perevochtchikova, Hernández y Avila-Foucat (2018) que las condiciones estructurales impiden la reproducción familiar a partir de una sola actividad, los hogares diversifican sus estrategias en distintos sectores. Otro trabajo sobre estrategias de las familias campesinas en Pueblo Nuevo, municipio de Acambay, Estado de México, evidencia que las actividades ejercidas por los pobladores para contribuir al gasto familiar no son netamente agropecuarias, sino que implementan otros tipos complementarios, albañilería, talabartería, carpintería, fletes y mudanzas, por mencionar algunos (Magdaleno, Jiménez, Martínez y Cruz, 20I4).

En la investigación sobre las estrategias de reproducción social de los productores de maíz en Tlaxcala, Damían et al. (2009) encontraron que, dados los procesos globales neoliberales, la producción de maíz ha sido afectada, por lo que los productores buscan alternativas que les permitan generar ingresos. Asimismo, Ramos, Parra, Hernández, Herrera y Nahed (2009) señalan en su publicación que los medios de vida de las familias de Oxchuc, Chiapas, México, inciden en la diversificación de tres estrategias desarrolladas: la agricultura, el empleo no agrícola y la migración, llegando a ser multiactivos; sin embargo, estas familias tienen una gran dependencia de las transferencias gubernamentales.

Como se puede observar en estos trabajos, la diversificación es sinónimo de sobrevivencia para las familias rurales; no obstante, cada comunidad tiene sus propias estrategias y actividades para lograr un desarrollo. Por ello, el objetivo de este trabajo es determinar las actividades económicas que llevan a cabo las familias productoras del sector agropecuario de la comunidad de Tanhuato como parte de las estrategias de desarrollo rural. El supuesto es que las familias diversifican la siembra de cultivos como estrategia de reproducción; además, el establecimiento de empresas comerciales en la región muestra un carácter benéfico porque genera empleos y reactiva la economía local.

En la comunidad de estudio se pudo apreciar que los productores, a través de la diversificación de los cultivos, han podido hacer uso de sus capacidades y potencialidades como estrategia para su supervivencia, lo que incluye la siembra de maíz, trigo, alfalfa, jitomate, cebada, sorgo, avena, chile jalapeño y cebolla principalmente. Asimismo, aunque en menor proporción, las mujeres y hombres de la comunidad están participando en trabajos asalariados de las empresas que se han instalado en la región, esto como parte de las dinámicas económicas que llevan a cabo las familias para solventar su seguridad alimentaria y asegurar el desarrollo de la unidad doméstica y, como consecuencia,
Este documento se divide en cinco partes. Después de esta introducción, se realiza una revisión de la literatura, en la que se presentan las estrategias de producción, la economía campesina y el desarrollo rural. Luego, se plantea la estrategia metodologíca, donde se justifica la elección de los productores encuestados y las empresas estudiadas. En la cuarta sección se presentan los resultados, posteriormente en la discusión se establecen semejanzas o diferencias entre los resultados y los antecedentes consultados y en el último apartado se plantean las principales conclusiones y recomendaciones.

\section{Marco Teórico}

\section{I. Estrategias de Reproducción}

La reproducción social "se refiere a una estrategia compartida y solidaria para lograr continuidad de la unidad doméstica y de la familia en el tiempo. La reproducción simple de las condiciones de existencia no descarta aspiraciones y estrategias de progreso". (López, 2008. p. 93). A su vez, se entiende como estrategia al proceso a través del cual los miembros de las unidades familiares hacen uso de combinaciones cada vez más diversas de sus recursos y activos (Niehof, 2004). Con base en lo anterior, las estrategias de reproducción que utilizan los productores resultan un tema relevante de indagar porque, a pesar de los cambios y el establecimiento de empresas agropecuarias en la región, éstos continúan trabajando en sus tierras y realizan diferentes actividades para sobrevivir, las cuales siempre se han llevado a cabo, pero con el paso de los años algunas se han modificado o desaparecido dependiendo de la disponibilidad de los recursos con los que cuenta cada unidad familiar. Por lo tanto, no se puede disociar la participación de la familia como ente principal en la reproducción, ya que requiere reproducirse biológica $y$, sobre todo, socialmente; es decir, reproducir las cualidades que le permitan conservar su posición y situación en el universo social donde se encuentra inserta (Bourdieu, 2004; Magdaleno et al., 20I4; Oliveira y Salles, 2003).

Por ello, las estrategias de las que se valen los productores, como lo expresan Rojas et al. (20l4), forman parte de un sistema más extenso de reproducción, de carácter social, económico, cultural y medio ambiental, producto de una forma específica de organización a escala local, pero integrada a su vez en un sistema económico global y dominante con el que interactúa de continuo, y en el que se busca una incorporación a actividades de mayor rentabilidad.

Los productores de Tanhuato han decidido implementar sus capacidades y conocimientos para desarrollar diversas actividades económicas, políticas, sociales y culturales, con el objetivo de reproducirse y de permanecer en las dinámicas 
socioeconómicas del país, del estado y de su comunidad: "rescatan la dimensión activa e inventiva de la práctica, y las capacidades generadoras del habitus; esta perspectiva de análisis recupera al agente social productor de las prácticas y su capacidad de invención e improvisación ante situaciones nuevas" (Gutiérrez, 2015, p. 49). Los productores ante los cambios económicos, políticos y sociales que van surgiendo deben adaptarse para poder sobrevivir; es entonces que, en lugar de permanecer paralizados y sin esperanza, toman decisiones a partir de sus propios recursos para afrontar las dificultades y contrariedades que se presentan en la vida cotidiana con la finalidad de asegurar la supervivencia, satisfacer las necesidades diarias o mejorar su nivel de vida (Guzmán, 2005; Palerm, 2008; Pepin-Lehalleur y Rendón, 1989).

En el estudio realizado por Mora y Cerón (2015) sobre diversificación de ingresos en el sector rural, se encontró que el impacto generado por la pluriactividad es significativo; el $80 \%$ de esta derrama se aprovecha para la supervivencia, y el resto se acumula. Por ello, la importancia para los pobladores rurales de diversificar las actividades resalta en tanto asegura la alimentación y el suplemente de necesidades básicas.

De esta manera cada unidad familiar realiza sus propias estrategias de reproducción porque éstas dependen de los recursos, habilidades, destrezas, capacidades, con las que cuenten; por ello se dice que las estrategias de reproducción son cambiantes, adaptativas e inventivas. Cada unidad familiar de la comunidad realiza diferentes actividades para poder reproducirse, entre las que destacan las agrícolas, como la siembra de alfalfa, hortalizas y maíz principalmente, la producción pecuaria y trabajos asalariados, recursos que se utilizan para financiar los proyectos de la unidad familiar y no los de cada uno de los integrantes (Sacco-Dos y Velleda, 2007).

\subsection{Economía Campesina}

Los productores durante años han buscado efectuar diversas actividades para lograr la sobrevivencia de la unidad familiar. Una de las principales es la producción agropecuaria, transmitida por generaciones y que en muchas familias mexicanas es el pilar de la reproducción ya que contribuye no solo a la obtención de capital sino a la sustentación alimenticia de manera directa; una porción se utiliza para autoabasto y el excedente se comercializa para la adquisición de productos no generados por los propios productores, así como para satisfacer diferentes necesidades básicas.

Los productores llevan a cabo actividades económicas principalmente con la intención de satisfacer sus necesidades y no como una ganancia acumulativa; es decir, el pensar campesino en el aspecto productivo-comercial difiere del empresarial capitalista, este último busca en todo momento la utilidad de lo invertido y la mayor retribución, mientras que el primero quiere conseguir la seguridad alimentaria $y$, solo cuando el tamaño de la producción lo permite, realiza la venta externa de los productos: "la búsqueda de excedentes no es el objetivo principal, y en caso de estar presente, deberá negociar su preponderancia con muchos otros factores y prioridades" (Landini, 201 I, p. 9). A su vez, Chayanov, Kerblay, Thorner y Harrison (1987), y Santacoloma (2015) coinciden en que la economía campesina no se basa en la ganancia de capital netamente sino en obtener la satisfacción de las necesidades de la familia, a través de diferentes actividades ya sean intra o extra prediales.

Empero, la estabilidad económica de la comunidad no deja de estar expuesta a los cambiantes procesos y demandas de las políticas de mercado y del Estado, que tienden a excluir, o en incluso explotar, a este tipo de economías, disminuyendo apoyos y créditos, devaluando los precios de los productos agropecuarios locales por debajo de los internacionales e incrementando recursos para apoyar a los grandes productores (Rubio, 2013; Shanin, 1976). Por mencionar un ejemplo, a principios del año 2000 los subsidios de gobierno federal se entregaron a grandes $y$ medianos productores de maíz, impulsando este tipo de producción y dejando de lado a la producción campesina (Rubio, 2013). Las investigaciones consultadas confirman la existencia de casos en el mismo escenario en los que se beneficia a los grandes empresarios (Appendini y Quijada, 2013; Chauvet y González, 2008; Suárez, 2017).

Es por ello que los campesinos buscan diversificar sus cultivos, porque, en caso de que alguno de los que hayan sembrado no favorezca el precio del mercado, pueden apoyarse con la comercialización de otros o utilizarlos para el abasto de la unidad familiar, y de esta manera disminuir la compra de artículos de primera necesidad. Este tipo de estrategia económica ha funcionado durante generaciones para lograr la reproducción; es importante señalar que no es homogénea entre los distintos casos, sino que cada unidad familiar o región tiene sus propias particularidades, ya que depende de los aspectos culturales, económicos, sociales y políticos en los que se encuentren insertos.

Lo que caracteriza a la economía campesina del sistema capitalista principalmente es la administración, que por lo general está a cargo del jefe de familia, pero consensada con el cónyuge, los hijos o los padres. La satisfacción de necesidades para la reproducción de la unidad familiar. La mano de obra empleada es el trabajo de la propia familia, y utilizan los recursos propios (tierra, herramientas, 
conocimientos) para la producción agropecuaria.Siembran y crían una variedad de plantas y animales. La comercialización es local o regional.

\subsection{Desarrollo Rural}

El concepto de desarrollo durante varias décadas ha tenido diversas interpretaciones, que pudieran agruparse por etapas definidas a partir de los paradigmas dominantes que les dieron origen. Kay (200I) distingue cinco, los cuales divide en: estructuralismo, modernización, dependencia, neoliberalismo y neoestructuralismo. Por su parte, Ellis y Biggs (2005) dividieron el termino desarrollo por décadas; en los años cincuenta surge el modelo económico dual; en los sesenta refiere a la modernización; en los setenta, la intervención del estado; en los ochenta, la liberación del mercado; en los noventa, participación y empoderamiento; $y$ en el dos mil surge el concepto de medios de vida sustentable. Castillo (2008) lo clasificó en cuatro paradigmas: economía dual (revolución verde), dependencia estructural (campesinistas y descampesinistas), neoliberalismo (la nueva ruralidad) y estrategias de vida (las estrategias de supervivencia).

Se entiende entonces que el término "desarrollo" se relaciona con la situación económica, social o política que se presente en determinado momento histórico, y principalmente se ha orientado hacia dos perspectivas, una es el enfoque de los países hegemónicos que consideran como desarrollo el crecimiento tecnológico, la acumulación de riquezas y el consumo; la otra visión lo entiende como la integración holística de las localidades para el bienestar o buen vivir de las unidades familiares (Esteva, 2000; López, 2008; Viola, 2000). Zárate (2005) explica que el desarrollo es un proceso que genera el crecimiento de los individuos, grupos y comunidades mediante sus propias capacidades analíticas y recreativas, y que favorecen la participación autogestiva para lograr un desarrollo integral. Max-Neef, Elizalde y Hopenhayn (1986) consideran importante que el desarrollo se visualice a escala humana, porque desde este enfoque se da énfasis a la satisfacción de las necesidades individuales y comunitarias, autodependencia de los individuos, de los procesos globales a los locales y de la analogía del ser humano con la naturaleza y la tecnología, de tal manera que se pueda "ser una persona sana, educada, productiva, creativa, y ver respetados tanto la dignidad personal como los derechos humanos" (Pérez de Cuellar, 1996, p. 8).

Las propias comunidades tienen "posibilidades y responsabilidades para promover el desarrollo" (Garofoli. 1995, p. II3), porque son los habitantes quienes conocen sus capacidades y recursos para implementar estrategias que cubran las necesidades básicas y garanticen el acceso a 130 las sinergias entre los distintos actores que forman parte del bienestar rural, "implicando la integración armónica entre producción y medio ambiente, entre políticas públicas y privadas, entre actividades agrícolas y no agrícolas, entre espacios territoriales y culturales, entre desarrollo económico, humano y ecológico" (IICA, ASDI y Cider, 2001. p 8). Por lo tanto, es trascendental que se revalorice la visión del desarrollo rural como una alternativa de vida viable, desde un enfoque político descentralizado, sustentable y autogestivo (Pérez, 2001). En este caso, la comunidad estudiada ha trabajado desde sus capacidades, perspectivas y enfoques para lograr el desarrollo de las unidades familiares y de su comunidad, a través de una amplia diversidad de estrategias que le permitan asegurar su reproducción.

\section{Metodología}

El trabajo de investigación se realizó en la localidad Tanhuato de Guerrero, que se localiza al suroeste del Estado de Michoacán de Ocampo, México, entre los paralelos $20^{\circ} \mathrm{Il}$ ' y $20^{\circ} 22^{\prime}$ de latitud norte; los meridianos $102^{\circ} 13^{\prime}$ y $102^{\circ} 27^{\prime}$ de longitud oeste; altitud entre 1.600 y $2.000 \mathrm{~m}$. Limita al norte con el municipio de Vista Hermosa, el estado de Jalisco y el municipio de Yurécuaro; al este con los municipios de Yurécuaro y Ecuandureo; al sur con los municipios de Ecuandureo e Ixtlán; al oeste los municipios de Ixtlán y Vista Hermosa (INEGI, 20I0). Se encuentra a $172 \mathrm{~km}$ de Morelia, la capital del estado. Cuenta con una extensión de $226,23 \mathrm{~km}^{2}$ y representa el 0,38 por ciento del total del Estado (INFDM, 2009) (Figura I). Se comunica con la autopista de occidente México-Guadalajara, por las carreteras federales 15 y 37, en sus tramos Morelia-Zamora y Carapan-La Piedad.

Las unidades de producción del municipio son alrededor de 1.826 (INEGI, 2007). Los principales cultivos que se siembran según datos de SIAP-SAGARPA (2016) son: alfalfa verde, avena forrajera, calabacita, cebada grano, cebolla, chile verde, ejote, frijol, garbanzo grano, maíz grano, sorgo grano, tomate rojo, camote, tomate verde y trigo grano.Asimismo, cuenta con 23I unidades de producción pecuaria (SINIIGA, 2017), donde tienen: bovinos, porcinos, ovinos, caprinos, gallinas y guajolotes (SIAP-SAGARPA, 2016).

La metodología que se llevó a cabo en esta investigación fue del tipo cualitativo, y exploratoria descriptiva: "los estudios exploratorios sirven para obtener información sobre la posibilidad de llevar a cabo una investigación más completa respecto de un contexto particular" (Hernández, Fernández y Baptista, 2006, p. 101). Asimismo, la investigación descriptiva "mide, evalúa o recolectan datos sobre diversos conceptos del fenómeno a investigar" (Hernández et al. 2006, p. 102). 


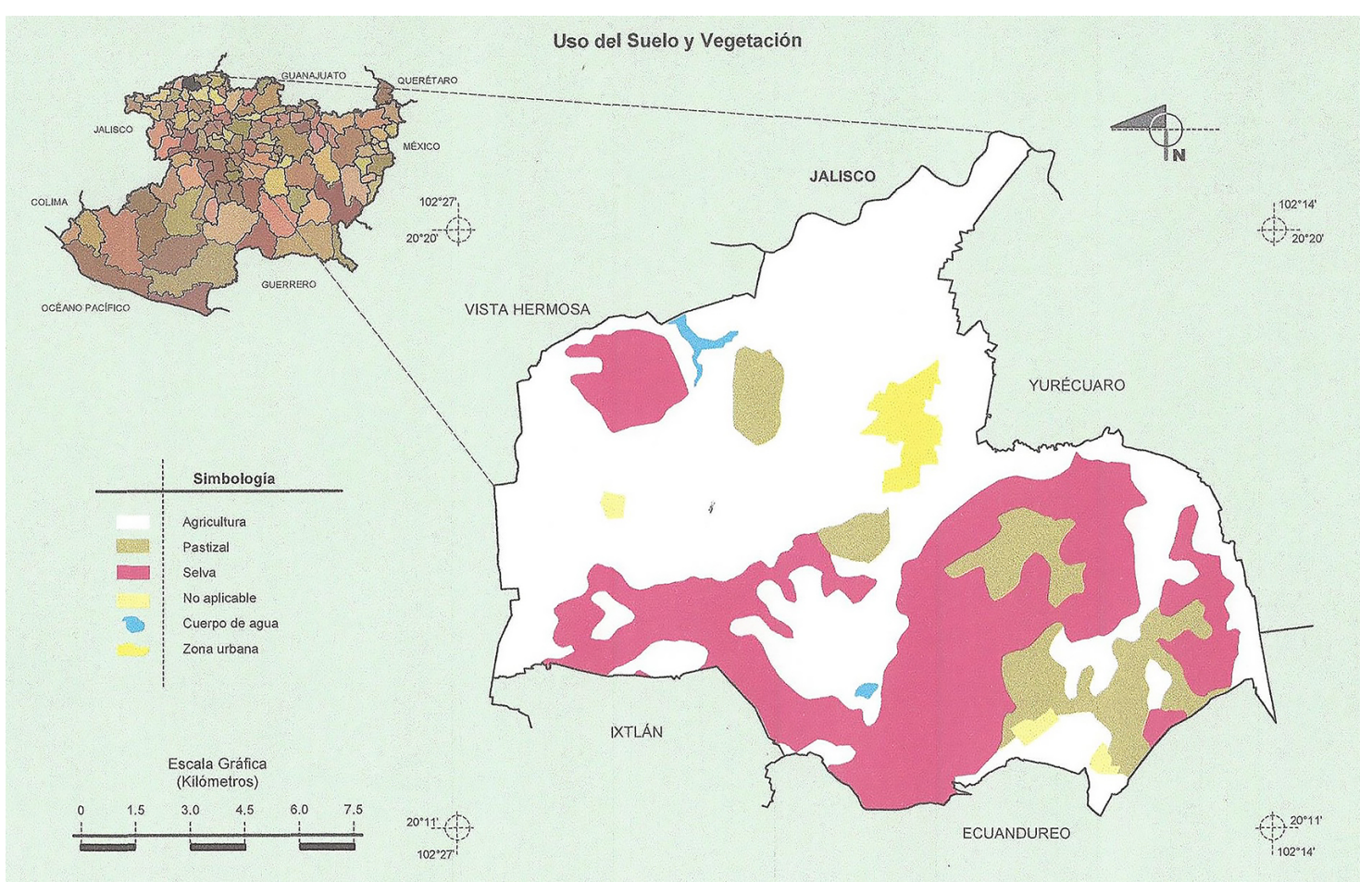

Figura I. Ubicación, uso de suelo y vegetación de Tanhuato

Fuente: Instituto Nacional de Estadística y Geografía (INEGI, 20 I0).

La determinación de la muestra se hizo mediante la técnica no probabilística "bola de nieve" o "avalancha", la cual consiste según, Martín y Salamanca (2007), en contactar informantes claves del lugar donde se pretenda realizar la investigación, posteriormente solicitar recomendación para entrevistar a otro individuo, y así sucesivamente.

El tamaño de la muestra fue de 40 personas, y se aplicaron 37 encuestas a los productores agropecuarios de la comunidad; de éstas, 10 se realizaron a manera de entrevista, ya que facilitan la comunicación porque se hacen directamente entre el entrevistador y el entrevistado (Monje, 20I I). Asimismo, se hicieron tres encuestas a los directivos de las empresas Su Karne, Productos del Campo Hermanos Gómez y Agrícola Vázques. De forma complementaria se llevaron a cabo recorridos de campo en las unidades productivas, se realizó la observación que permitió visualizar las actividades cotidianas, actitudes, expectativas y conductas de las personas (Rojas, 2013). El trabajo de campo se llevó a cabo de julio de 2016 a marzo de 2017, se utilizaron 65 ítems para el instrumento que se aplicó a los productores y 22 para el de los directivos de las empresas. La información obtenida se sistematizó en el programa Excel $尺$ y posteriormente se analizó; también, se hizo una revisión bibliográfica de artículos científicos, capítulos de libros, libros y datos estadísticos para conocer información sobre la comunidad y la importancia de la diversificación de actividades económicas para el desarrollo rural.

\section{Resultados}

\section{I. Los productores y las estrategias de reproducción de la unidad familiar}

Los productores son los actores principales en las actividades agropecuarias de la comunidad, un productor es una persona que toma sus propias decisiones y el control administrativo de su producción sobre el uso de los recursos con los que cuenta. Con la ayuda del trabajo de sus familias y un equipo simple, produce principalmente para su propio consumo y cuando existe excedente, lo comercializa; de esta forma atienden sus obligaciones para con quienes detentan el poder político y económico (Shanin, 1976).

El principal recurso que las familias productoras requieren para llevar a cabo la siembra de sus cultivos es la tierra, la cual representa identidad, arraigo y sobrevivencia. En la comunidad de estudio se pudo estimar que menos de la mitad de los encuestados (4I\%) tienen sus parcelas desde hace más de 20 años, y que han recibido las mismas como herencia, pues antes pertenecieron a sus padres o abuelos, 
y desde siempre las han trabajado. Es de resaltar que la mayoría (59\%) tienen menos de 20 años con las parcelas, porque algunos las compraron para sembrar cultivos comerciales con la intención de obtener mayores ingresos como aporte a las estrategias de desarrollo.

Los productores más jóvenes son los que están abiertos al cambio de los cultivos tradicionales a los comerciales, $y$ en la comunidad de estudio se observó que la mayoría son menores de 50 años. La edad promedio es de 46 años; $67 \%$ se coloca entre un rango de 30 a 50 , y el resto son mayores a $5 \mathrm{I}$ años. Esto muestra que la mayoría de las familias se encuentran en una etapa de ciclo familiar "en crecimiento" y una minoría en su etapa de "madurez" (Guzmán, 2005). El $61 \%$ de las familias cuenta entre tres y cuatro personas en el hogar, $28 \%$ de cinco a seis, y $11 \%$ entre dos y una. Las familias en la etapa de crecimiento en su generalidad tienen hijos que viven en el hogar y van a la escuela, lo que genera mayores gastos en la unidad familiar $y$, por consiguiente, les es indispensable contar con seguridad alimentaria y de desarrollo.

Una de las estrategias que llevan a cabo los productores encuestados para asegurar su alimentación y desarrollo es la diversificación de cultivos, porque así pueden obtener cosechas e ingresos de las distintas siembras "cuando las cosas salen bien"; es decir, que exista clima adecuado, demanda de productos y precio de mercado rentable, principalmente. En casos de que las circunstancias sean adversas para alguno de los cultivos, cuentan con los otros para asegurar el ingreso familiar. Asimismo, utilizan parte de lo que siembran para consumo de la unidad doméstica. Uno de los productores relató:"una vez nos pegó la helada bien fuerte y se quemó toda la alfalfa. Se pudo rescatar algo, pero casi no. Lo bueno que teníamos el maíz, y éste aguantó un poco, pudimos cosechar y ya con eso nos recuperamos de la pérdida de la alfalfa" (Héctor Miguel, comunicación personal, 2016).

Puede afirmarse entonces que en Tanhuato los productores agropecuarios diversifican las actividades agrícolas (Figura 2) con la intención de obtener mayores ingresos para abastecer sus necesidades básicas, y para ello procuran cultivos rentables. Sin embargo, los productores encuestados perciben la existencia de un conjunto de problemas estructurales adversos para su desarrollo, de los cuales los principales son: la comercialización de los productos a un precio injusto (según lo expresa el $90 \%$ de los participantes), el cambio climático y sus efectos (sequía, granizadas, exceso de lluvia, etc.) que en ocasiones genera pérdidas de los cultivos (78\%), y los altos precios de los insumos (95\%).

Todas estas circunstancias motivan a los productores a implementar medidas que les permitan reducir costos de producción para incrementar sus ingresos, las cuales van desde la búsqueda de diferentes proveedores de insumos con costos más accesibles, hasta conseguir nuevos canales de comercialización con los que puedan obtener precios de venta mayores a los ofertados en los mercados locales. Como ejemplo, el $97 \%$ de los encuestados realizan las compras fuera de la comunidad porque han observado que los precios son menores en las localidades circunvecinas.

No obstante, aun con los efectos del cambio climático, el alto precio de insumos y la baja retribución por sus productos, los encuestados argumentan que seguirán sembrando. Como mencionó un productor en la entrevista:

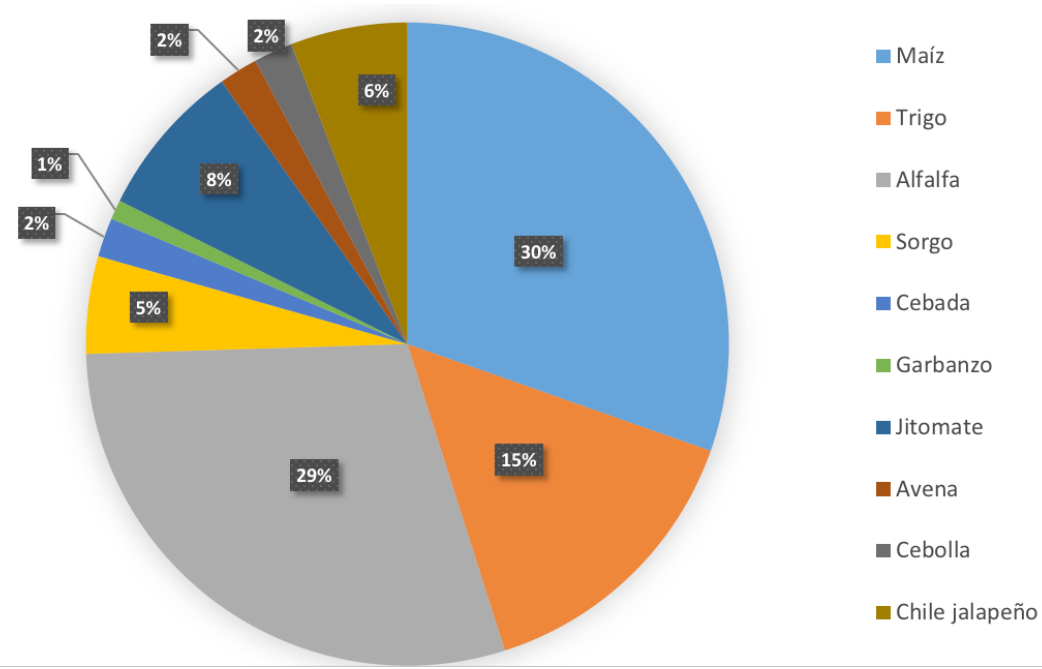

Figura 2. Porcentaje de productores que siembran diferentes cultivos

Fuente: Elaboración propia con datos de las encuestas realizadas de julio 2016 a marzo 2017. 
"Qué le vamos a hacer, no sabemos hacer otra cosa más que sembrar, y esto nos da para ir comiendo" (Pedro, comunicación personal, 2016). Las encuestas permitieron constatar que la actividad económica predominante es la agricultura, y los productores consideran esta ocupación como parte importante de las estrategias de desarrollo rural, lo que involucra también un aspecto de identidad histórica, pues los encuestados perciben a la agricultura como una actividad ancestral, que también prevén como el futuro del municipio:

\section{Con sus cultivos como el maíz hibrido y el criollo y otro maíz que le nombraron pipitillo; el frijol, el trigo, la cebolla, el sorgo, el jitomate, el chile y quién no recuerda el aprecio que tuvo el cultivo del camote, y no se diga el cultivo de la alfalfa de hace algunos años que también tuvo su prestigio (Guillén, comunicación personal, 20 I7).}

$58 \%$ expresó que la superficie de siembra se ha mantenido constante desde hace aproximadamente 25 años, 20\% mencionó que va en aumento, y $22 \%$ considera que ha disminuido, lo que indica que la mayoría (78\%) no ha visto una disminución de las siembras. Este dato coincide con lo presentado por SIAP-SAGARPA (2018) en el municipio de Tanhuato, porque la superficie de siembra del año 2003 al 2016 incrementó en un 37\%, de 9.426 a 15.036 hectáreas. Sin embargo, el panorama que se presenta a nivel estatal difiere, pues esa escala disminuyó en un 9\%; en el año 2003 se tenía una superficie de siembra de 815.800 , y en el 2016 , de 740.770 hectáreas.
El cultivo que más se siembra y cosecha es el maíz amarillo (Figuras 3 y $\underline{4}$ ), debido a que forma parte de la dieta de los animales que crían y de la demanda general que existe en la región. En la comunidad, este grano se produce específicamente para la comercialización; sin embargo, las familias encuestadas cuentan también con ganado (así lo manifestó $17 \%$ de los encuestados), por lo que utilizan una parte para alimentar a los animales. El cultivo que le sigue respecto a la superficie de siembra en la comunidad es la alfalfa. Sobre este producto, uno de los encuestados refirió: "hace algunos años tuvo su prestigio, a tal grado que la variedad sembrada, por su calidad, llegó a denominársele 'Tanhuato'” (Guillén, comunicación personal, 20l7); es decir, esta variedad se originó en la comunidad de estudio, lo que indica la importancia productiva que tiene esta leguminosa. El trigo ocupa el tercer lugar en la producción, se utiliza como alimento del ganado y para la venta en diferentes mercados de la región. Estos tres cultivos son los que llevan más años de siembra en la comunidad; después le siguen el sorgo y el jitomate, y por último, el chile jalapeño (Figura 5).

Esta diversidad de cultivos se ha implementado como parte de la diversificación para mejorar los ingresos. Los cultivos varían dependiendo de la superficie de siembra, y los productores pueden cambiar la producción de un cultivo por otro, o incluso dejar de sembrar alguno por temporadas y después volverlo a cultivar. Esto depende a su vez de la demanda del mercado, de los costos de producción, del cambio climático y de la disponibilidad de tierra. No obstante, las tierras tienen que estar ocupadas, como los productores dicen, pues ello es necesario para

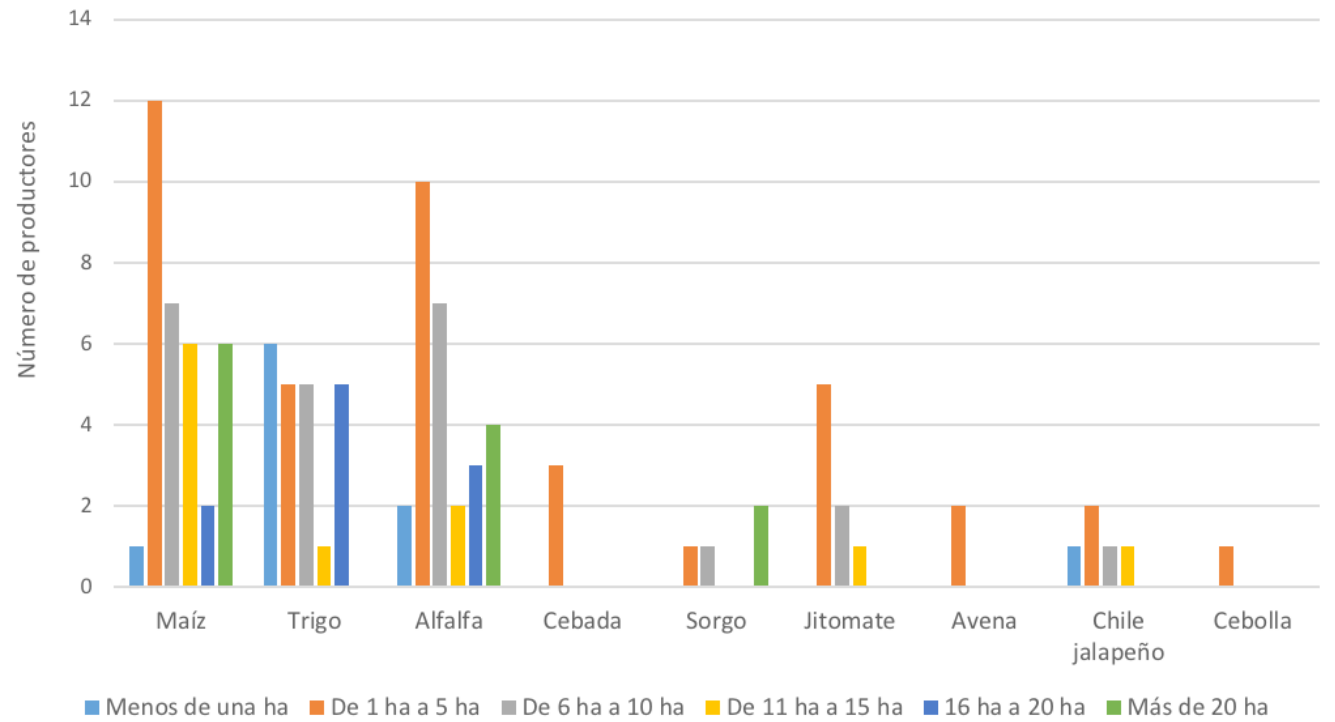

Figura 3. Superficie de siembra de los cultivos

Fuente: Elaboración propia con datos de las encuestas realizadas de julio 2016 a marzo 2017. 


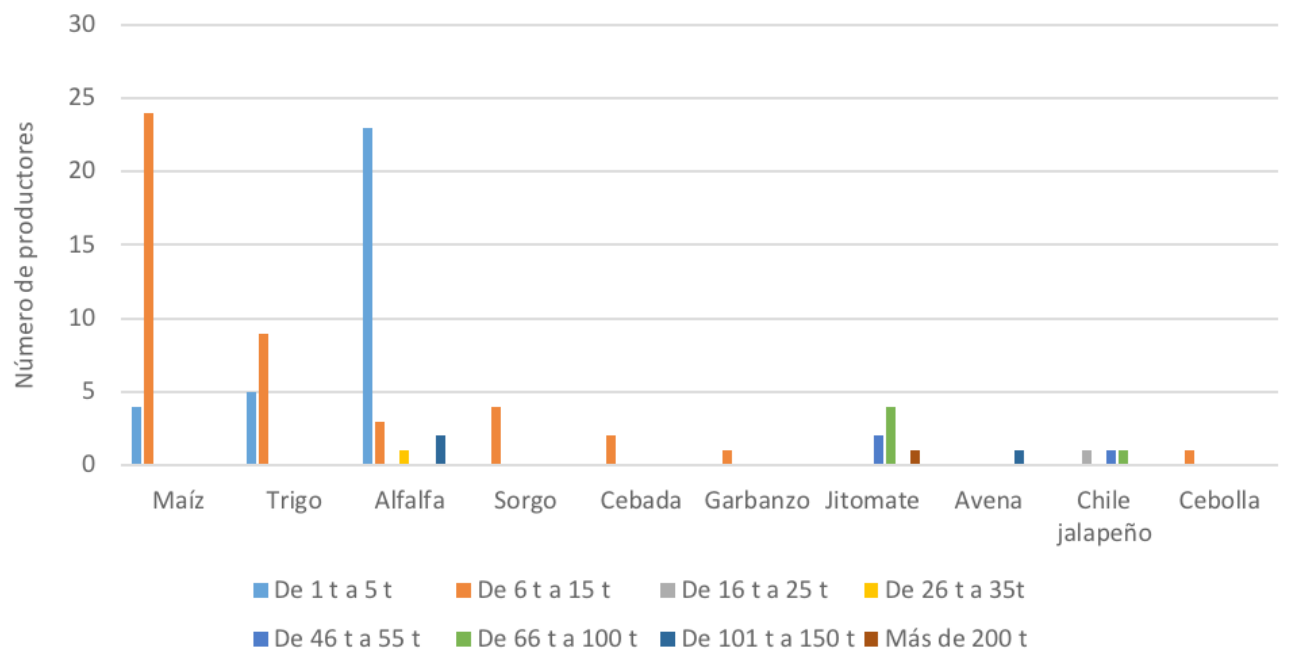

Figura 4. Cosecha de los cultivos

Fuente: Elaboración propia con datos de las encuestas realizadas de julio 2016 a marzo 2017.

$$
12
$$

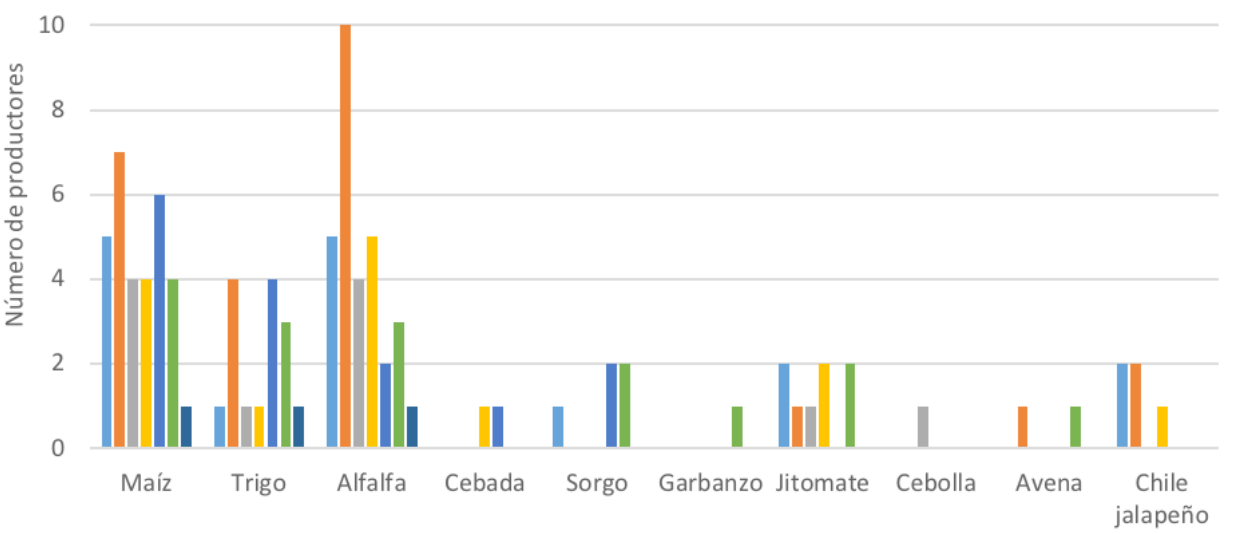

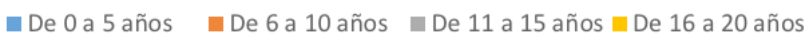

- De 21 a 30 años — De 31 a 40 años ש ;ás de 40 años

Figura 5. Tiempo de sembrar los cultivos

Fuente: Elaboración propia con datos de las encuestas realizadas de julio 2016 a marzo 2017.

obtener ganancias, y además recibir apoyos por parte de las instituciones gubernamentales; según las encuestas realizadas, $43 \%$ recibieron algún tipo de beneficio gubernamental, principalmente de Procampo. El número de productores beneficiados es de 1.668 en todo el municipio (SAGARPA-Procampo, 2017).

La mayoría los productores encuestados (32\%) comentan que siembran y quieren seguir haciéndolo; otros dicen que siembran y quieren continuar sembrando, pero que sus hijos busquen otras alternativas de ingresos (27\%); están continúen con los cultivos (27\%); y, por último, los que siembran y quieren dejar de sembrar (14\%). En conjunto, es un $86 \%$ el que desea continuar con la producción de sus cultivos porque les ha generado ingresos y con ello pueden seguir manteniendo sus tierras y abastecer sus necesidades básicas.

Estas actividades han formado parte de las estrategias de reproducción para lograr un desarrollo en la unidad familiar $y$, por consecuencia, de la comunidad. Los productores están siendo dinámicos e innovadores en la búsqueda de alternativas económicas, sociales y políticas 
para la satisfacción de sus necesidades, lo que ha generado cambios en la actitud y hábitos de vida de las familias de los productores. Esto permite afirmar que los agricultores son personajes activos en el desarrollo de sus comunidades debido a que "tienen capacidades analíticas y creativas que favorecen la consecución de sus metas y la consolidación de procesos de crecimiento y desarrollo integral" (Zarate, 2005, p. 196).

\subsection{Venta de productos agrícolas de los productores encuestados}

La comercialización de productos agropecuarios de los pequeños productores requiere de un canal de distribución dinámico, pues necesitan recuperar el dinero invertido para realizar la siguiente siembra y asegurar la cobertura de sus necesidades básicas. Sin embargo, estos productores por lo general reciben un pago menor por la venta de sus cosechas en comparación con el que reciben los intermediarios por los mismos productos, ya que el productor carece de estrategias relacionadas con la información del mercado, administración, infraestructura, organización y apoyos institucionales para lograr una adecuada comercialización y mejor retribución de sus productos.

La venta de los productos agrícolas en la comunidad tiene diferentes canales de comercialización, siendo los principales la central de mercados, los intermediarios de la región y la venta a pie de parcela (Figura 6). Los canales que utilizan los productores dependen de varios factores: el producto a vender, el precio ofertado, la demanda, la necesidad del productor de acceder a recursos económicos de forma inmediata o a realizar una venta a crédito. Estos canales de distribución son los que conocen con mayor seguridad y a los que pueden ingresar directamente, siempre buscando la mayor utilidad de la producción cosechada.

Los mercados agropecuarios son muy elásticos porque, cuando existe un cambio en el precio, éste se refleja significativamente en el volumen de venta; es decir, es muy sensible a las variaciones en los precios, lo que genera altos riesgos de pérdidas y ganancias. No obstante, los especialistas en comercializar conocen muy bien las tendencias, el margen de ganancia de los productos, los momentos y lugares adecuados para ofertar. El intermediarismo como agente económico se ha vuelto una necesidad para los pequeños productores porque, a pesar de que pagan los productos a menor precio, están dispuestos a comprar sus mercancías todo el año, ya sea en la misma localidad o mercados locales, lo que origina una disminución en la inversión por parte del productor (muchas veces, un gasto de este tipo les es imposible de costear) en caso de que deba transportar a otros mercados. "Esta actividad, a pesar de que afecta el ingreso económico del productor, es común, lo que permite que el intermediario aproveche esta situación para beneficiarse económicamente" (Sánchez, Zagoya y Leal, 2015, p. 5).

El intermediarismo resulta rentable, a pesar de los riesgos que implica esta actividad por factores como la caída de la demanda de productos, robos, accidentes, pérdidas, entre otros. Esta actividad se ve como necesaria porque existe una desvinculación productiva y de comercialización del productor, por lo que este último solamente recupera sus costos de producción, y el intermediario adquiere ganancias de hasta un " $50 \%$ sobre el costo de producción" (Romero, Huerta y Reyes, 2008, p. 659). Los productores rurales se han apoyado en este tipo de agentes económicos

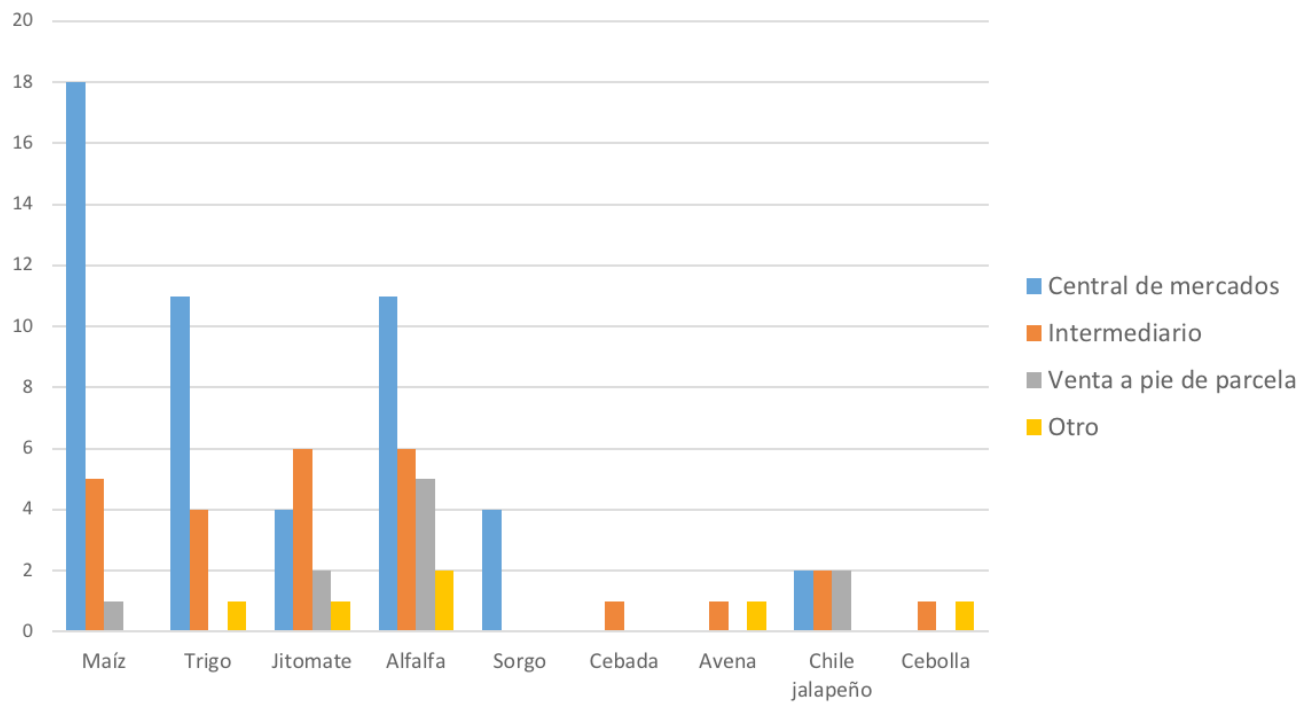

Figura 6. Lugares donde comercializan los cultivos

Fuente: Elaboración propia con las encuestas realizadas de julio 2016 a marzo 2017. 
para comerciar sus productos, a pesar de que reciben un pago inferior al que es ofertado por el mercado (Tabla I), "el productor no tiene la posibilidad de fijar su precio, al contrario, es tomador de precios" (Arvizu et al., 2014, p. 693).

Tabla I.

Precios por kilogramo

\begin{tabular}{ccc}
\hline Cultivo & $\begin{array}{c}\text { Precio pagado al } \\
\text { productor (Peso } \\
\text { mexicano) }\end{array}$ & $\begin{array}{c}\text { Precio en el } \\
\text { mercado nacional } \\
\text { (Peso mexicano) }\end{array}$ \\
\hline Maíz & 3.4 & 5.2 \\
Trigo & 3.7 & 4.3 \\
Alfalfa & 2.6 & 3.6 \\
Sorgo & 3.2 & 4.5 \\
Cebada & 4.2 & 5.2 \\
Jitomate & 3.5 & 6.2 \\
Avena & 2.3 & 6.3 \\
Chile jalapeño & 8.2 & 12 \\
Cebolla & 6 & 7.5 \\
\hline
\end{tabular}

Fuente: Elaboración propia con las encuestas a productores, 2016 y Sniim, 2016.

Estas desigualdades en los precios se deben a la falta de conocimiento de los productores en aspectos relacionados con la comercialización y la mercadotecnia, falta de organización, de recursos gubernamentales para financiar la capacitación, asesoría y respaldo para elaborar contratos de compra-venta, de conocimiento y experiencia de los técnicos para mejorar las prácticas de mercado y buscar diversos canales de comercialización a favor de los productores, de organización por parte de los productores para formar cooperativas o asociaciones comerciales, y de empresas u organizaciones para procesar productos agropecuarios y darles un valor agregado (Romero et al., 2008; Sánchez et al., 2015).

Los productores -agricultores continúan trabajando solos en los aspectos comerciales, ya que no cuentan con un sistema que les pueda proporcionar capacitaciones en comercialización, administración, organización y/o apoyos gubernamentales a través de estrategias que permitan llegar al consumidor final o en su caso a los intermediarios de los mercados nacionales, quienes ofertan mejores precios de los productos. Como mencionan los entrevistados:

Es lo que conocemos y pues, cuando podemos ingresar a un mercado mejor y nos dejan, lo hacemos, pero cuando no podemos llevar la mercancía a otros lugares por falta de recurso, conocimiento o delincuencia, pues la vendemos donde siempre y en la mayoría de las ocasiones a precios bajos (Roberto, comunicación personal, 2016).

Esto los obliga a ceñirse a los requerimientos del mercado local y cumplirlos para que puedan vender su mercancía, de lo contrario les castigan todavía más el precio. Las principales características requeridas son: humedad (47\%), calidad (32\%), tamaño ( $18 \%)$, facturas $(2 \%$ y vida de anaquel duradera (1\%). Los productores por cuenta propia buscan diferentes alternativas de producción y comercialización, con la intención de mejorar la productividad de sus cultivos $y$, por consiguiente, obtener mayores ingresos. Un estudio alrededor del cultivo de amaranto menciona que "los productores por su propia cultura, comodidad o por desconocimiento del proceso de comercialización del amaranto, lo venden al intermediario, sin tener una información precisa de que los transformadores están dispuestos a pagar una cantidad mayor por su producto" (Sánchez et al., 2015, p. 14).

\section{Dentro del modelo vigente, la prioridad ha sido mantener una política de libre mercado que, además de repetir los errores estructurales en la definición de subsidios, no considera diferencias entre las actividades territoriales, económicas, culturales o sociales del medio rural respecto al resto de los sectores (Delgadillo y Torres, 2009. p. 59)}

generando la polarización de los productores, porque en muchas ocasiones los mayores subsidios se emplean para las grandes empresas, y a los pequeños les apoyan con programas asistencialistas que han disminuido paulatinamente, y que realmente no les beneficia en la producción. Como ejemplo, el recurso aportado por Procampo en la comunidad "en años anteriores era de $\$ 930$ por hectárea, y desde el año 2017 se les otorga $\$ 450$ si tienes menos de 10 hectáreas, y si tienes más de 10 , son $\$ 150$, y si están sembradas con alfalfa, son \$90" (Martín, comunicación personal, 2016), causando, según los mismos productores encuestados, desinterés en tales programas, y que prefieran no realizar las gestiones necesarias para recibirlo, pues gastan más en copias y transporte que lo que reciben.

\subsection{Trabajos asalariados}

En la región de Tanhuato se han instalado empresas agropecuarias que ofertan sus productos en el ámbito regional, nacional e internacional. Esta localidad se encuentra en un punto estratégico para la comercialización debido a que tiene vías de acceso adecuadas y se localiza muy cerca de la ciudad de Guadalajara, lo que permite movilizar los 
productos fácilmente. De las encuestas realizadas a las personas que laboran en las empresas Su Karne, Agrícola Vázques y Productos del Campo Hermanos Gómez se pudo determinar que la gente busca este tipo de trabajos porque les ofrecen un salario seguro, prestaciones y cercanía con la localidad de origen. Las principales prestaciones que mencionaron los directivos que requieren los trabajadores son el seguro social y los aguinaldos'.

Los directivos encuestados de las tres empresas consideran que la apertura de estos negocios ha generado un crecimiento económico en la región, pues se han creado miles de empleos; por ejemplo, tan solo estas tres empresas contratan un total de 3.700 empleados (Tabla 3), permitiendo a los mismos mayores ingresos para abastecer las necesidades de la unidad familiar. Además, parte de los insumos son adquiridos directamente con los productores de las localidades aledañas (Tabla 2), tales como maíz, forraje, agroquímicos, tubería de PVC y material de limpieza.

Tabla 2.

Porcentaje de insumos que compran a diferentes proveedores

\begin{tabular}{ccc}
\hline $\begin{array}{c}\text { Compra de } \\
\text { insumos }\end{array}$ & $\begin{array}{c}\text { Empresa } \\
\text { Agrícola } \\
\text { Vázques }\end{array}$ & $\begin{array}{c}\text { Productos del } \\
\text { Campo Hermanos } \\
\text { Gómez }\end{array}$ \\
\hline Localidades cercanas & 45 & 15 \\
Otros municipios & 20 & 5 \\
Otros estados & 25 & 30 \\
Otros países & 10 & 50 \\
\hline
\end{tabular}

Fuente: Encuestas a representantes de las empresas, 2017.

Asimismo, los encuestados de las tres empresas manifestaron que los precios que pagan por los insumos comprados en las localidades cercanas son pactados con los mismos proveedores, y las facturas se liquidan en tiempo y forma, de acuerdo con el crédito o el compromiso tratado. No obstante, los precios ofertados por la empresa Su Karne se perciben como no justos por los productores de maíz y forraje, ya que éstos expresan que los precios de compra son muy bajos.

Tabla 3.

Número de empleos ofertados por las empresas

\begin{tabular}{ccc}
\hline $\begin{array}{c}\text { Empresa Su } \\
\text { Karne }\end{array}$ & $\begin{array}{c}\text { Productos del } \\
\text { Campo Hermanos } \\
\text { Gómez }\end{array}$ & $\begin{array}{c}\text { Agrícola } \\
\text { Vázques }\end{array}$ \\
\hline 2.000 & 1.200 & 500
\end{tabular}

Fuente. Encuestas a representantes de las empresas, 2017.

Los puestos que desempeñan los empleados de las tres empresas son: operarios, operadores, jornaleros de producción, zanqueros, fumigadores, barredores, plastiqueros, empacadores, estibadores, cargadores, etiquetadores, supervisores, entre otros. En las empresas agrícolas, la mayoría de los empleados son mujeres, un $54 \%$, y $46 \%$ hombres. Según opinión de los propios encuestados, ello se debe a que las mujeres son percibidas por los empleadores como más responsables, creativas, comprometidas con la empresa, y tienen necesidad de un trabajo diferente a la siembra de cultivos porque éste lo realiza principalmente el jefe del hogar.

De las tres empresas, se observa que tanto Agrícola Vázques como Productos del Campo Hermanos Gómez son propiedad de productores de las localidades cercanas donde se establecieron los negocios, personas que siempre han vivido del trabajo en el campo, ya sea en México o en Estado Unidos. Conocen las necesidades de la gente y son quienes ofrecen mejores precios a los proveedores y productores de la localidad, con la intención expresa de que todos se beneficien:"somos amigos desde hace mucho tiempo" (Directivo de la empresa Agrícola Vázques, 20l6). Estas empresas producen especialmente tomate grape, saladette, perita, mini kumato, zima, nébula; así como, pepino europeo. Su venta es tanto nacional como internacional. La empresa Su Karne, por su parte, es propiedad de un empresario de otro estado, Sinaloa, que desde hace 50 años ha estado trabajando principalmente en la industria de la carne bovina. Esta compañía aplica una política empresarial, por lo que compra a los productores de la región los insumos a bajos precios. La venta de los productos la realiza en el ámbito local, regional, nacional e internacional.

Los productores encuestados refirieron que la instalación de empresas agropecuarias en la región genera empleos, pero que estos no impactan significativamente la diversificación de ingresos de las unidades familiares de la localidad estudiada. Solamente el $1 \%$ tiene algún familiar que trabaja en las empresas agropecuarias.Argumentan que la mayoría de los empleados de estas tres empresas son personas que viven en localidades circunvecinas que, por lo general, no cuentan con tierra de uso agrícola, por lo que se ven en la necesidad de buscar este tipo de empleos; además, manifiestan que los salarios son muy bajos. Por tanto, las familias de los encuestados encuentran su sustento principalmente en la producción agrícola mediante la diversificación de los cultivos.

La reactivación de la economía local es necesaria para el crecimiento de la producción, el acceso a los alimentos, generación de ingresos y bienestar de la población; por ello, es ineludible que los gobiernos de los países importadores de alimentos implementen políticas públicas encaminadas a reforzar la producción interna de alimentos, porque los mercados internacionales son estructuras económicas 
que buscan el beneficio monetario a costa de la cadena de producción, aun si tienen que dejar sin comer a miles o millones de habitantes. Como bien lo mencionan Delgadillo y Torres (2009), el desarrollo de una comunidad no solo se trata de gestionar el ingreso de grandes consorcios, sino de reactivar la economía local mediante la generación de empresas familiares y adquirir una innovación territorial encaminado al desarrollo rural.

\section{Discusión}

La diversificación de actividades en los hogares rurales es parte de las estrategias de reproducción que las familias llevan a cabo para incrementar sus ingresos y con ello lograr un desarrollo. Estas estrategias están integradas en un sistema extenso donde se incluyen aspectos sociales, culturales, ambientales y económicos, elementos propios de una economía global en la que los productores deben buscar actividades rentables para vivir. Estas actividades se realizan, no obstante, desde la visión de la economía campesina; es decir, los productores siembran y trabajan para obtener ingresos principalmente para satisfacer sus necesidades alimenticias y básicas, ya que no ven la producción o los ingresos como una acumulación de riqueza. Partiendo de lo anterior, en este estudio se reflexionó sobre las actividades económicas que llevan a cabo las familias productoras del sector agropecuario de la comunidad de Tanhuato. El supuesto es que los productores diversifican sus prácticas de siembra de cultivos como estrategia de reproducción; además, el establecimiento de empresas comerciales en la región resulta benéfico porque genera empleos y reactiva la economía local.

Los datos obtenidos del estudio arrojaron que la principal actividad que llevan a cabo los productores encuestados es la producción agrícola, misma que se ha trasmitido por generaciones, $y$ es realizada a partir de sus propias capacidades y recursos, para lo que implementan maniobras desde su propia lógica para subsistir en la economía capitalista. Las principales estrategias implementadas son: el establecimiento de cultivos comerciales, la decisión de cuál, cuándo, dónde y cómo sembrar un cultivo, la búsqueda de diferentes proveedores de insumos a bajo costo y la forma de conseguir nuevos canales de comercialización donde los precios de venta sean mayores a los ofertados en los mercados locales. Sin embargo, esta última maniobra no es de fácil implementación, pues los encuestados refieren que es difícil ingresar a nuevos mercados por falta de conocimiento, lo cual ha orillado a algunos a seguir ofertando sus productos en los mercados locales $y$ a los intermediarios de la región, ocasionando que la producción sea comercializada a bajos precios y que los agentes económicos obtengan las mayores ganancias. Sánchez et intermediarismo es una práctica común que afecta el ingreso económico de los productores primarios. Para que se dé una solución y disminuya la dependencia de estos agentes es necesario que los productores se capaciten continuamente, consigan asistencia técnica y acompañamiento profesional.

Con relación a las empresas establecidas en la localidad como parte de la diversificación de actividades, los directivos encuestados de éstas señalan que se han generado empleos y que compran algunos insumos a los pobladores de la comunidad como aporte a los ingresos de los habitantes. No obstante, los productores encuestados argumentaron lo contrario, pues perciben que la comercialización de productos agrícolas (maíz, alfalfa, trigo, sorgo, cebada, esquilmos y subproductos) de la región no repuntó debido al bajo precio de compra que ofrecen las empresas, $y$ por ello prefieren ofertarlos en otros mercados. Asimismo, un mínimo porcentaje de los miembros de la unidad familiar de los encuestados combinan actividades no agropecuarias como asalariados en estas empresas, aunque su participación es baja porque manifiestan que el pago es muy bajo. Esto difiere de la investigación de Mora y Cerón (2016) en la que encontraron que las familias rurales tienen un mayor potencial para participar en el empleo asalariado.

Por su parte Rello y Saavedra (2013) determinaron que las actividades no agrícolas son la principal fuente de ingresos de varias zonas rurales, contrario a lo que sucede en este estudio, ya que los productores encuestados manifestaron que la producción agrícola es su principal ingreso y que la seguirán realizando por muchos años más. Puede entonces afirmarse que los productores de la comunidad de estudio buscan mejorar sus ingresos a través de diversas estrategias, desde sus propias capacidades, recursos y conocimientos; es decir, han sido y seguirán siendo partícipes de su propio desarrollo a pesar de los problemas que se les presentan.

Es importante recalcar que se han publicado algunos trabajos relacionados con la diversificación de ingresos en las zonas rurales, cada uno con sus propias características y actores, pero con coincidencias puntuales en cuanto a la transcendencia de continuar con las actividades agropecuarias. Además, señalan la importancia de implementar apoyos gubernamentales para que los productores y sus familias mejoren su nivel de bienestar y desarrollo (Rello y Saavedra, 2013; Mora y Cerón, 2016).

\section{Conclusiones}

Se concluye que en la comunidad de Tanhuato la mayoría de los productores se dedican a la siembra desde hace más de 20 años y los principales cultivos que producen son: maíz, trigo y alfalfa; sin embargo, diversifican su producción como parte de las estrategias de reproducción para asegurar 
y favorecer la mejora de sus condiciones materiales y lograr el desarrollo de la unidad familiar. Entre los cultivos implementados en tal diversificación destacan: cebada, sorgo, jitomate, avena, chile jalapeño y cebolla. Esta diversificación de cultivos les ha ayudado a salir adelante de los principales problemas a los que se tienen que enfrentar y que los encuestados han visualizado como prioritarios: los altos costos de insumos, los bajos precios de comercialización $y$, en los últimos años, el cambio climático que ha generado incluso pérdidas de sus cosechas. Con respecto de esto último, cuando de algún cultivo no se obtiene cosecha, pero otros sí han dado producción, o si el precio de uno es más bajo en comparación con otro, pueden compensarse, de lo cual pueden echar mano para incrementar sus ingresos. Por lo anterior, se puede constatar que la diversificación de la siembra de cultivos es una estrategia de reproducción para esta localidad.

En la venta de la producción agrícola el principal canal de comercialización son los compradores de la central de mercados, y después el intermediarismo.A pesar de que los precios que pagan estos dos agentes económicos son bajos, los productores encuestados no buscan otros porque no tienen el conocimiento para ingresar a nuevos canales de distribución, ya sea por falta de capacitación en aspectos relacionados con la comercialización y la mercadotecnia, de asesoría y respaldo para elaborar contratos de compraventa, de organización, entre otros.Además, los productores buscan la seguridad de sus cultivos para generar ingresos o, en su caso, el auto abasto para sus familias, y no persiguen netamente la ganancia de modo capitalista, sino que pretenden generar recursos para sobrevivir y lograr un desarrollo. Por tanto, puede afirmarse que se encuentran en una lógica de la economía campesina porque no comercian para acumular riqueza sino para satisfacer sus necesidades básicas.

A pesar de la instalación de empresas agropecuarias en el municipio, éstas no han formado parte importante de la diversificación de actividades de los productores encuestados. Muy pocos miembros de las familias laboran en tales empresas, y son escasos los productores que les venden parte de su producción porque el precio de compra es bajo. Por tanto, se rechaza el supuesto de que hay una reactivación de la economía local por la generación de empleos y que las empresas sean una alternativa para la venta de la producción.

Es necesario que los productores continúen diversificando los cultivos para hacer frente a las problemáticas actuales de la producción agrícola, así como desarrollar nuevas fuentes de ingresos económicos para lograr abastecer sus necesidades básicas. De igual manera, es fundamental que los gobiernos municipal, estatal y federal impulsen programas para incrementar la producción agropecuaria, la comercialización de los productos agrícolas y la organización en la compra de insumos. Las políticas para la instalación de empresas agrícolas en zonas rurales deben buscar el beneficio de los pobladores de la comunidad y reglamentar los precios de compra para los insumos de los productores de la región.

Una de la limitante que se presentó durante el desarrollo de la investigación fue la desconfianza de los encuestados al realizar el trabajo de campo, ya que no tenían mucha disponibilidad para acceder a compartir la información, principalmente en los aspectos sobre costos de producción, precios de venta, avíos con los que cuentan y las cabezas de ganado. Esto aunado a la situación de inseguridad que se vive en esta zona.

La información recopilada en este estudio da pie a continuar con investigaciones sobre las diversas actividades que realizan los habitantes de las zonas rurales como estrategias de desarrollo, en las cuales se puedan comparar características, capacidades, recursos y necesidades de cada comunidad, con la finalidad de conocer las actividades más representativas y adecuadas en cada zona, y con ello se contribuya al bienestar de las unidades familiares, además de identificar las principales problemáticas a las que se enfrentan los productores agrícolas con la intención de implementar políticas públicas en beneficio de los habitantes de las localidades.

\section{Notas}

I. El aguinaldo es una gratificación que, de acuerdo con la Ley Federal del Trabajo Artículo 87, le corresponde al patrón abonar a los trabajadores por lo menos quince días de su salario cada año, este deberá pagarse antes del día veinte de diciembre.

\section{Conflicto de intereses}

Los autores declaran no tener ningún conflicto de intereses.

\section{Referencias bibliográficas}

I. APPENDINI, Kristen y QUIJADA, María Guadalupe. La crisis alimentaria y su impacto en México: el maíz. En: RUBIO, Blanca. La crisis alimentaria mundial Impacto sobre el campo mexicano. México: Miguel Ángel Porrúa, 2013. I19-149 p.

2. ARVIZU, Ezequiel; JIMÉNEZ, Leobardo; JIMÉNEZ, Mercedes A; QUISPE, Anibal; VILLA, Manuel R. y ÁVILA, José. A. Análisis de producción y comercialización de hortalizas: caso del Mercado de Huixcolotla, Puebla. En: Revista Mexicana de Ciencias Agrícolas. junio-agosto, 2014, vol. 5, no. 4, p. 687-694. https://www.redalyc.org/ html/2631/263I304760I2/ 
3. BOURDIEU, Pierre. Coisas Ditas. Ira. Reimpresión. Brasil: Brasiliense, 2004. 235 p. ISBN 85-I I-08069-4.

4. CASTILLO, Olga Lucia. Paradigmas y conceptos del Desarrollo Rural. 2. ed. Bogotá, Colombia: Pontificia Universidad Javeriana, 2008. 61 p. https://mundoroto.files.wordpress.com/201 I/05/paradigmas-yconceptos-de-desarrollo-rural.pdf

5. CHAYANOV, Alexander; KERBLAY, B., THORNER, Daniel y HARRISON, M. Chayanov y la teoría de la economía campesina. D.F. México: Siglo XXI, 1987. $194 \mathrm{p}$.

6. CHAUVET, Michelle y GONZÁLEZ, Rosa Luz. Biocombustibles y cultivos biofarmacéuticos: ¿oportunidades o amenazas? En: El cotidiano. 2008. vol.23, no. 147, p. 5 I-61.http://www.elcotidianoenlinea.com.mx/ pdf//4707.pdf

7. DAMIÁN, Miguel Ángel; RAMÍREZ, Benito; PARRA, Filemón; PAREDES, Juan Alberto; GIL, Abel; LÓPEZ, Jesús Francisco y CRUZ, Artemio. Estrategias de reproducción social de los productores de maíz de Tlaxcala. En: Estudios sociales. 2009. vol. 17, no. 34, p. II2-146. http://www.scielo.org.mx/scielo.php?script=sci arttext\&pid=SO $188-45572009000200004$

8. DELGADILLO, Javier y TORRES, Felipe. La gestión territorial como instrumento para el desarrollo rural. En: Estudios Agrarios. 2009. no. 23, p. 55-73. http://www.pa.gob.mx/publica/rev 42/ANALISIS/ Javier\%20Delgadillo_6.pdf

9. ELLIS, Frank y BIGGS, Stephen. La evolución de los temas relacionados al desarrollo rural: desde la década de los años ' 50 al 2000. En: Organizações Rurais e Agroindustriais Universidade Federal de Lavras. 2005. vol. 7, no.I, p. 60-69. https://ageconsearch.umn.edu/ bitstream/44034/2/revista_v7_nl_jan-abr_2005_5.pdf

10. ELLIS, Frank. Rural Livelihoods and Diversity in Developing Countries. Oxford: Oxford University, 2000. 287 p. ISBN 978-0-19-829696-6.

II. ESTEVA, Gustavo. Desarrollo. En: ANDREU Viola. Antropología del Desarrollo. Teoría y estudios etnográficos en América Latina. Barcelona: PAIDOS, 2000.67-10I p.

12. GAROFOLI, Gioacchino. Desarrollo económico, organización de la producción y territorio. En: VÁZQUEZ, Antonio y GAROFOLI, Gioacchino. Desarrollo económico local en Europa. Madrid, España: Colegio de Economistas, 1995. I13-123 p.

13. GUTIÉRREZ, Alicia. Pobre'...como siempre: estrategias de reproducción social en la pobreza. Córdoba Argentina: Universidad Villa María-Eduvim, 2015. 382 p. ISBN 978-987-699-157-5.

14. GUZMÁN, Elsa. Resistencia, Permanencia y cambio. Estrategias campesinas de vida en el poniente de Morelos. Morelos, México: Plaza y Valdés-UAEM, 2005. 314 p. ISBN 970-722-4I6-9.

15. HERNÁNDEZ, Roberto; FERNÁNDEZ, Carlos y BAPTISTA, Pilar. Metodología de la Investigación. 4 ed. México: Mc Graw Hill Interamericana, 2006.850 p. ISBN 970-10-57-53-8.

16. IICA. Situación de la seguridad alimentaria en las Américas. Documento para alimentar el diálogo de la $42^{\mathrm{a}}$. Asamblea General de la Organización de los Estados Americanos, 2012. https://www. oas.org/es/sre/dai/sociedad_civil/Docs/OEA\%20Seguridad\%20
17. IICA, ASDI y CIDER. Género en el Desarrollo Rural Sostenible, Una respuesta a un nuevo paradigma, 200I. https://www.sudamericarural. org/images/en_papel/archivos/generoeneldesarrollosostenible.pdf

18. INEGI. Censo Agropecuario, 2007. inegi.org.mx/programas/cagf/2007/

19. INEGI. Compendio de información geográfica municipal Tanhuato Michoacán de Ocampo, 2010. http://www3.inegi.org.mx/contenidos/ app/mexicocifras/datos_geograficos/16/16086.pdf

20. INFDM. Enciclopedia de los municipios de México. Gobierno del estado de Michoacán, México, 2009. http://www.inafed.gob.mx/work/ enciclopedia/EMMI6michoacan/index.html

21. KAY, Cristóbal. Los paradigmas del desarrollo rural en América Latina. En: GARCÍA, Francisco. El mundo rural en la era de la globalización: incertidumbres. $X$ Coloquio de Geografía Rural de España de la Asociación de Geógrafos Españoles, 200I. 337-430 p.

22. LANDINI, Fernando. Racionalidad económica campesina. En: Mundo Agrario. Julio-diciembre, 20II. vol. 12, no. 23, p. I-26. http://www.scielo.org.ar/scielo.php?script=sci arttext\&pid=SI5|5-599420110002000|4

23. LÓPEZ, Lorenzo Alejandro.Al filo del surco: Campesinado y desarrollo sustentable. Coahuila, México: Guzmán Editores- Universidad Autónoma Agraria Antonio Narro, 2008. 198 p. ISBN 6070002997, 9786070002991 .

24. MAGDALENO, Edgar; JIMÉNEZ, Mercedes A; MARTíNEZ, Tomas y CRUZ, Bartolome. Estrategias de las familias campesinas en Pueblo Nuevo municipio de Acambay, Estado de México. En: Agricultura, Sociedad y Desarrollo. Abril-junio, 2014. vol. II, no. I, p. I67-179. https://www.colpos.mx/asyd/volumen I I/numero2/asd-13-096.pdf

25. MARTíN, María Cristina y SALAMANCA, Ana Belén. El muestreo en la investigación cualitativa. En: Nure-investigación. Marzo-abril, 2007. no. 27, p. I-4.www.nure.org/OJS/index.php/nure/article/view/340/330

26. MAX-NEEF, Manfred; ELIZALDE, Antonio y HOPENHAYN, Martín. Desarrollo a escala humana. Opciones para el futuro. Santiago de Chile- CEPAUR y Fundación Dag Hammarskjöld Montevideo: Editorial Nordan Comunidad, I986. 96 p. (Development dialogue).

27. MONJE, Carlos Arturo. Metodología de la investigación cuantitativa y cualitativa Guía didáctica. Colombia: Universidad Surcolombiana, 20II. p. 217. https://www.uv.mx/rmipe/files/2017/02/Guia-didacticametodologia-de-la-investigacion.pdf

28. MORA, José Jorge y CERÓN, Hazael. Diversificación de ingresos en el sector rural y su impacto en la eficiencia: evidencia para México. En: Cuadernos del Desarrollo Rural. Julio-diciembre, 2015. vol. 12, no. 76, p. 57-8I. http://www.scielo.org.co/pdf/cudr/v/2n76/v12n76a03.pdf

29. NIEHOF, Anke.The Significance of Diversification for Rural Livelihood Systems. En: Food Policy. 2004. vol. 29, no. 4, p. $321-338$.

30. OLIVEIRA De, Orlandina y SALLES,Vania. Reflexiones teóricas para el estudio de la producción de la fuerza de trabajo. En: DE LA GARZA, Enrique. Tratado Latinoamericano de Sociología del Trabajo. D.F., México: El colegio de México, Facultad Latinoamericana de Ciencias Sociales, Universidad Autónoma Metropolitana y Fondo de cultura económica, 2003. p. 619-643. 
31. OSEGUERA, David y ESPARZA, Luís L. Significados de la seguridad y el riesgo alimentarios entre indígenas purhépechas de México. En: Desacatos. Septiembre-diciembre, 2009. no. 3I, p. II5-I36. http:// www.scielo.org.mx/scielo.php?script $=$ sci_arttext\&pid $=\mathrm{S} 1607$ $\underline{050 \times 2009000300008}$

32. PALERM, Ángel. Clásicos y contemporáneos en Antropología. Antropología y marxismo. 3 ed. México: Ciesas / Clásicos de la Casa Chata, Universidad Autónoma Metropolitana y Universidad Iberoamericana A.C., 2008. 347 p. ISBN 978-968-496-639-0

33. PEPIN-LEHALLEUR, Marielle y RENDÓN, Teresa. Reflexiones a partir de una investigación sobre grupos domésticos campesinos y sus estrategias de reproducción. En: DE OLIVEIRA, Orlandina; PEPIN-LEHAULLEUR, Marielle y SALLES,Vania. Grupos domésticos y reproducción cotidiana. México: El Colegio de México / Porrúa, 1989. $107-126 \mathrm{p}$.

34. PEREVOCHTCHIKOVA, María; HERNÁNDEZ, José Álvaro y AVILAFOUCAT, Veronique Sophie. Recursos naturales y diversificación productiva en cuatro localidades rurales del Estado de Oaxaca, México. En: Cuadernos de Desarrollo Rural. Junio, 2018. vol. 15, no. 8I, p. I-25. https://doi.org/10.1I|44//averiana.cdr /5-8I.rndp

35. PÉREZ, Edelmira. Hacia una nueva visión de lo rural. En: GIACARRA, Norma. Una nueva ruralidad en América Latina. Buenos Aires, Argentina: CLACSO, 200I. 17-29 p.

36. PÉREZ DE CUELLAR, Javier. Nuestra Diversidad Creativa. Informe de la Comisión Mundial de Cultura y Desarrollo.Versión resumida. París, Francia: UNESCO. 1996, 66 p.

37. RAMOS, Pedro Pablo; PARRA, Manuel Roberto; HERNÁNDEZ, Salvador; HERRERA Obeimar Balente y NAHED, José. Estrategias de vida, sistemas agrícolas e innovación en el municipio de Oxchuc, Chiapas. En: Geografía Agrícola. Enero-junio, 2009. no. 42, p. 83-106. https://www.redalyc.org/articulo.oa?id=757/2192007

38. RELLO, Fernando y SAAVEDRA, Fernando. Diversificación productiva y transformación estructural en México: estudios de caso de tres regiones. En: Investigación económica. Abril-junio,2013. vol. 72, no. 284, p. III-I29. http://www.scielo.org.mx/pdf/ineco/v72n284/ v72n284a5.pdf

39. RIVAS, Carlos A; GARZA, Laura E; MEJÍA, Juana M. Una experiencia de productores sobre retención de riqueza y su contribución para reducir el intermediarismo. En: Agricultura, Sociedad y Desarrollo. Julio-septiembre, 2018. vol. 15, no. 3, p. 379-397. http://www.scielo. org.mx/pdf/asd/v15n3/1870-5472-asd-15-03-379-en.pdf

40. ROJAS, Raúl. Guía para realizar investigaciones sociales. 9 ed. México: Plaza y Valdés, 2013. 437 p. ISBN 968-856-262-5

4I. ROJAS, Coral; MARTÍNEZ, Beatriz; VÁZQUEZ, Verónica; CASTAÑEDA, Patricia; ZAPATA, Emma y SÁMANO, Miguel Ángel. Estrategias de reproducción campesina, género y valoración del bosque en Lachatao, Oaxaca, México. En: Agricultura, Sociedad y Desarrollo. Enero-marzo, 2014. vol. II, no. I, p. 7I-9I. https://www.redalyc.org/ pdf/3605/360533098005.pdf

42. ROMERO, Omar; HUERTA, Manuel y REYES, Delfino. ¿Metodología para conformar una empresa comercializadora de productos agropecuarios como estrategia para el desarrollo de zonas agrícolas? En: Mexicana de Agronegocios. Julio-diciembre, 2008. no. 23, p. 658666. https://www.redalyc.org/articulo.oa?id $=\mid 4102310$

43. RUBIO, Blanca. La crisis alimentaria en México. En: RUBIO, Blanca. La crisis alimentaria mundial Impacto sobre el campo mexicano. México: Miguel Ángel Porrúa, 2013.53-83 p.

44. SACCO DOS, Flavio y VELLEDA, Nadia. Pluriactividad y agricultura familiar en Brasil: el caso de Río Grando do Sul. En: Cepal. diciembre, 2007. no. 93, p. 157-173. https://www.researchgate.net/publication/28213022_Pluriactividad_y_agricultura_familiar_en_Brasil_el_ caso_de_Rio_Grande_do_Sul

45. SÁNCHEZ, Josset; ZAGOYA, Joaquín y LEAL, Saúl. Impacto de la dinámica del intermediario en el ingreso del productor de amaranto durante la comercialización en Tochimilco, Puebla. En: Observatorio de la Economía Latinoamericana. febrero, 2015. p. 2-16. http://www. eumed.net/coursecon/ecolat/mx/20I5/amaranto.html

46. SANTACOLOMA, Luz Elena. Importancia de la economía campesina en los contextos contemporáneos: una mirada al caso colombiano. En: Entramado. Julio-diciembre, 20I5. vol. II, no. 2, p. 38-50. https:// www.redalyc.org/pdf/2654/265443638004.pdf

47. SAGARPA- PROCAMPO. Beneficiarios de Procampo, 2017. http:// www.sagarpa.gob.mx/agricultura/Programas/proagro/procampo/Beneficiarios/Paginas/2013.aspx

48. SIAP-SAGARPA. Producción Agropecuaria, México, 2016. http://www. siap.gob.mx/cierre-de-la-produccion-agricola-por-cultivo/

49. SIAP-SAGARPA. Cierre agrícola, 2018. https://www.gob.mx/siap/acciones-y-programas/produccion-agricola-33119

50. SHANIN, Teodor. Naturaleza y lógica de la economía campesina. Traducido por Horacio González Trejo. Barcelona, España:Anagrama, $1976.85 \mathrm{p}$.

5I. SINIIGA. Estadística pecuaria PGN, 2017. http://www.pgn.org.mx/ programs/estadistica-bis.php

52. SNIIM. Precios del día de hoy, 2016. http://www.economia-sniim.gob. $\underline{\mathrm{mx}}$

53. SUÁREZ,Víctor. Rescate del campo mexicano organización campesina y políticas públicas posneoliberales. Ciudad de México, México: Itaca, 2017. 462 p. ISBN 978-607-9780I-7-3

54. VIOLA, Andreu. La crisis del desarrollismo y el surgimiento de la antropología del desarrollo. En:VIOLA, Andreu. Antropología del desarrollo. Teorías y estudios etnográficos del desarrollo. Barcelona, España: PAIDÓS, 2000. 9-63 p.

55. ZARATE, Mireya. Desarrollo Comunitario. En: SERRANO, Ricardo y GÓMEZ DEL CAMPO, José. Modelo de desarrollo humano comunitario, Sistematización de 20 años de trabajo comunitario. D.F., México: Plaza y Valdés, 2005. 193-214 p. 